\title{
Salicylsalicylic Acid Causes Less Gastroduodenal Mucosal Damage than Enteric-Coated Aspirin An Endoscopic Comparison
}

\author{
JAMES M. SCHEIMAN, MD, ELIZABETH M. BEHLER, ROSEMARY R. BERARDI, PHARM D, \\ and GRACE H. ELTA, MD
}

\begin{abstract}
The gastroduodenal mucosal damage caused by aspirin and nonsteroidal antiinflammatory drugs is a common clinical problem. We compared two medications designed to diminish mucosal damage: enteric-coated aspirin and salicylsalicylic acid (salsalate). Ten healthy volunteers were randomized to receive either $1.5 \mathrm{~g}$ salsalate twice a day or $650 \mathrm{mg}$ enteric-coated aspirin four times a day for six days and were then crossed over to the other drug after a one-week medication-free period. Endoscopic inspection of gastroduodenal mucosa was performed at entry and again after six days of drug therapy for each medicine. Mean serum salicylate concentrations taken before the morning drug dose were $11.2 \mathrm{mg} / \mathrm{dl}$ for enteric-coated aspirin and $18.1 \mathrm{mg} / \mathrm{dl}$ for salsalate. Only one of 10 subjects receiving salsalate developed mild (grade 1) mucosal damage while six of 10 receiving enteric-coated aspirin developed moderate to severe damage (grade $2-3)(\mathrm{P}=0.01)$. Symptoms were mild in both groups. We conclude that salsalate causes less gastroduodenal mucosal damage than enteric-coated aspirin.
\end{abstract}

KEY WORDS: salicylsalicylic acid; enteric-coated aspirin; gastroduodenal mucosal damage.

Salicylates are among the most widely used drugs in clinical practice. Aspirin remains the cornerstone of therapy for rheumatoid arthritis and other musculoskeletal disorders. The damaging effect of aspirin and nonsteroidal anti-inflammatory drugs on gastroduodenal mucosa is well known. Quantitation of aspirin-related mucosal damage can be assessed by endoscopic evaluation as well as by measurement of fecal blood loss. Both techniques have

\footnotetext{
Manuscript received June 6, 1988; revised manuscript received August 29, 1988; accepted August 31, 1988.

From the Division of Gastroenterology, Department of Internal Medicine, and College of Pharmacy, University of Michigan, Ann Arbor, Michigan.

Presented in part at the AGA, New Orleans, 1988.

Address for reprint requests: Dr. Grace H. Elta, University of Michigan Medical Center, 3912 Taubman Center, Ann Arbor, Michigan 48109-0362.
}

demonstrated a dose-response relationship between aspirin dose, mucosal damage, and ultimately the risk of chronic gastric ulcer (1). Buffered and enteric-coated aspirin preparations have been developed in an attempt to lessen gastroduodenal mucosal damage. Two studies have concluded that enteric-coated aspirin causes considerably less mucosal damage than either plain or buffered aspirin $(2,3)$.

Salicylsalicylic acid (salsalate), a salicylate ester of salicylic acid, was originally developed as a safer nonacetylated alternative to aspirin (4). All salicylates are hydrolyzed to salicylic acid. Unlike acetylsalicylate, salsalate yields two molecules of salicylic acid. Since the drug is insoluble in acidic gastric fluids, it is a stomach-bypassing salicylate as 
Table 1. Endoscopy Rating Scale

\begin{tabular}{cl}
\hline Grade & \multicolumn{1}{c}{ Description } \\
\hline 0 & Normal \\
1 & Less than 3 areas of mucosal hemorrhage or erosions \\
2 & $3-10$ areas of mucosal hemorrhage or erosion \\
3 & Widespread involvement or greater than 10 areas of \\
& erosions with active bleeding \\
\hline
\end{tabular}

is enteric-coated aspirin. Salsalate has been studied by both measurements of fecal blood loss (5-7) and the gastrocamera (8), an early endoscopic instrument, and reportedly shows little or no evidence of gastric mucosal damage. We have performed a randomized, single-blind endoscopic study of the gastroduodenal effects of enteric-coated aspirin and salsalate, two preparations designed to spare mucosa. This comparison may help to guide therapeutic choices between salicylate preparations.

\section{MATERIALS AND METHODS}

Ten healthy volunteers between the ages of 18 and 35 (seven males, three females) with no history of gastrointestinal disease, alcohol abuse, or regular aspirin or nonsteroidal antiinflammatory drug use were randomized to receive either salsalate $1.5 \mathrm{~g}(2 \times 750 \mathrm{mg}$ tablets $)$ orally twice a day or enteric-coated aspirin $650 \mathrm{mg}(2 \times 325 \mathrm{mg}$ tables) orally four times a day for six days. Subjects were instructed to avoid all other medicines and alcohol throughout the study. The doses administered are standard recommended doses in clinical practice. An initial endoscopy was performed prior to drug administration to assess mucosal integrity. A symptom diary was provided to record any occurrence of side effects in the subjects. After six days of drug administration, the AM medication was omitted on the seventh day and a serum salicylate concentration was drawn reflecting blood concentrations approximately $10 \mathrm{hr}$ after the preceding dose of medicine. Serum salicylate measurements were obtained by the Dupont automated clinical analyzer using the Natelson colorimetric technique. Endoscopies were performed by the same endoscopist blinded to the drug that the volunteer had been taking. The endosopic findings were graded using a modification of the gastroscopy rating scale of Lanza et al (2) (Table 1). Medication compliance was confirmed by return of dispensed medication for pill counts.

After a seven-day washout period, the subjects underwent an additional endoscopy to confirm resolution of any previous drug-induced changes and then were crossed over to the other medication. On the seventh day, a serum salicylate level was obtained and endoscopy was again performed.

Statistical analysis of endoscopy scores obtained after drug treatment was performed with the Wilcoxon signed rank test.

Informed written consent was obtained from all volunteers before participation. The sudy was approved by the
University of Michigan Human Use Committee, Ann Arbor, Michigan.

\section{RESULTS}

Endoscopic Findings. Only one volunteer (subject 10) had endoscopic evidence of mucosal damage on the initial endoscopy, two 6-mm antral erosions, prior to drug administration. Two subjects had minimal duodenal erythema on control endoscopy with no change in endoscopic appearance with drug administration. Two additional subjects had prepyloric areas of erythema $(<5 \mathrm{~mm}$ each), which resolved during drug administration. All volunteers had return to baseline endoscopic appearance after the one-week medication-free washout period.

After salsalate administration, only one of the 10 subjects developed any evidence of mucosal damage, which was only grade 1 severity (Table 2 ). This one subject received the salsalate in the first treatment period. Six of 10 subjects taking entericcoated aspirin developed gastroduodenal lesions: one with grade 2 damage and five with grade 3 lesions. Three of these six subjects were randomized to receive the enteric-coated aspirin in the first treatment period and three received it in the second treatment period. Using the Wilcoxon signed rank test, the difference in mucosal damage in entericcoated aspirin vs salsalate was statistically significant with $P=0.01$. One of the five subjects with grade 3 lesions developed a duodenal ulcer while receiving enteric-coated aspirin (subject 10); excluding this normal volunteer due to his baseline antral endoscopic abnormality does not alter the statistical significance of the difference in endo-

Table 2. Endoscopy Scores and Serum Salicylate Levels IN 10 VolunTEERS ON SALSALATE AND ENTERIC-COATED ASPIRIN

\begin{tabular}{|c|c|c|c|c|}
\hline \multirow[b]{2}{*}{ Subject } & \multicolumn{2}{|c|}{ Salsalate } & \multicolumn{2}{|c|}{ Enteric-coated aspirin } \\
\hline & $\begin{array}{c}\text { Endoscopy } \\
\text { score }\end{array}$ & $\begin{array}{c}\text { Salicylate } \\
\text { level }(\mathrm{mg} / \mathrm{dl})\end{array}$ & $\begin{array}{c}\text { Endoscopy } \\
\text { score }\end{array}$ & $\begin{array}{c}\text { Salicylate } \\
\text { level }(\mathrm{mg} / \mathrm{dl})\end{array}$ \\
\hline 1 & 0 & 38.8 & 0 & 10.0 \\
\hline 2 & 0 & 19.0 & 3 & 15.6 \\
\hline 3 & 0 & 10.0 & 2 & 6.6 \\
\hline 4 & 0 & 24.7 & 0 & 5.6 \\
\hline 5 & 0 & 16.5 & 0 & 8.9 \\
\hline 6 & 0 & 17.0 & 3 & 9.6 \\
\hline 7 & 1 & 16.3 & 0 & 12.2 \\
\hline 8 & 0 & 18.0 & 3 & 15.4 \\
\hline 9 & 0 & 6.9 & 3 & 14.1 \\
\hline $10^{*}$ & 0 & 13.4 & 3 & 13.8 \\
\hline
\end{tabular}

*Volunteer 10 had a score of 1 on each baseline endoscopy. All other baseline scores were 0 . 
scopy scores $(P=0.02)$. The distribution of mucosal damage in the seven volunteers who developed lesions always involved the stomach but also included duodenum in three of the six subjects on Ecotrin (including subject 10 who developed a duodenal ulcer).

Symptoms. All symptoms were graded in severity from 0 to 5 . Tinnitus was the only troublesome side effect of moderate severity in three of 10 subjects on salsalate. One other volunteer on salsalate had mild tinnitus. All other side effects were mild and did not occur daily but included nausea or heartburn in two volunteers on salsalate. Five of 10 subjects receiving enteric-coated aspirin developed mild side effects, including two with tinnitus, and one each with abdominal pain, heartburn, nausea, and minor epistaxis. The incidence of tinnitus was not associated with the serum salicylate values obtained.

Salicylate Levels. Mean fasting salicylate concentrations after six days of drug administration drawn approximately $10 \mathrm{hr}$ after the preceding dose were $18.1 \mathrm{mg} / \mathrm{dl}$ for salsalate and $11.2 \mathrm{mg} / \mathrm{dl}$ for entericcoated aspirin (Table 2). There was no association between salicylate levels and gastroduodenal damage.

\section{DISCUSSION}

The mechanism of aspirin-induced gastrointestinal mucosal damage appears, at least in part, to be interference with endogenous prostaglandin production with subsequent impairment of mucosal defense. Gastric acidity plays an important role in the mucosal damage once the normal barrier to mucosal $\mathrm{H}^{+}$ion back-diffusion is altered. Much of aspirin's effect on mucosal defense may be caused by the acetyl group, which acetylates and inhibits prostaglandin synthetase (9). The nonacetylated salicylates, such as salsalate, are very weak inhibitors of prostaglandin synthesis in vivo (10), yet are reportedly effective in rheumatologic diseases. This may be due to the effect of salicylates on other mediators of inflammation (11). Similarly, the lack of effect of nonacetylated salicylates on platelet function (12) is consistent with an absence of in vivo prostaglandin interference. Therefore, the gastrointestinal sparing effect of salsalate may be due, at least in part, to its lack of acetylation. In addition, a recent study (13) has suggested that salicylates alter acid secretion, which may also be important in the pathogenesis of aspirin-induced gastric damage. $\mathrm{Pa}$ renteral salicylic acid inhibits acid secretion to a much greater extent than acetylsalicylic acid. This correlates with a lack of gastric damage with the nonacetylated agent. When luminal $\mathrm{pH}$ was lowered by acid instillation in a rat model of salicylate damage, both salicylic acid and acetylsalicylic acid caused equivalent damage (13).

Another possible mechanism for the mucosal sparing effect of salsalate is its lack of gastric absorption. Salsalate is practically insoluble in the acid $\mathrm{pH}$ of the stomach but is freely soluble at neutral intestinal $\mathrm{pH}$. In contrast aspirin, in its nonionized form, can be passively absorbed in the stomach. Enteric-coated preparations, which are insoluble in acid but soluble at neutral intestinal $\mathrm{pH}$, reportedly cause less gastric mucosal damage than plain aspirin due to bypassing gastric absorption. Endoscopic evidence of damage with entericcoated aspirin still occurs but is less than that of plain aspirin in normal volunteers $(2,3)$. In rheumatic patients, enteric coating also leads to a lower frequency of gastric damage (14) but apparently not duodenal damage (15).

We performed an endoscopic comparison of two salicylate preparations both of which bypass gastric absorption. Our endoscopic observations demonstrate less gastroduodenal damage with salsalate than with enteric-coated aspirin in the doses administered. Only one subject developed mild mucosal damage on salsalate while six of 10 subjects taking enteric-coated aspirin had multiple mucosal lesions. The additional mucosal sparing effect of salsalate may be due to its nonacetylation, which differentially affects two processes: (1) prostaglandin synthesis and (2) acid secretion. Our endoscopic results are consistent with previous studies showing little fecal blood loss on salsalate therapy $(5,6)$.

The doses chosen for this study are standard doses used in clinical practice. It has been demonstrated that the average doses required to maintain plasma salicylate concentrations in antiinflammatory therapeutic range would be $5 \mathrm{~g}$ daily of aspirin versus $3.6 \mathrm{~g}$ daily of salsalate (16). Therefore, our study was actually biased against salsalate since our aspirin dose, $2.6 \mathrm{~g}$ daily, versus salsalate, $3.0 \mathrm{~g}$ daily, may have resulted in less than equivalent salicylate concentrations. The higher serum salicylate concentrations obtained with salsalate may reflect the doses used, the $10-\mathrm{hr}$ time interval from previous dose to blood sampling, or altered dissolution and absorption of the enteric-coated form. The frequent side effect of tinnitus on salsalate 
would again suggest that, if anything, our dosing regimen was biased against salsalate.

In conclusion, our study shows that salsalate causes less endoscopic evidence of mucosal damage than enteric-coated aspirin after six days of administration in healthy volunteers. Longer-term studies in rheumatic patients need to be performed to confirm these promising results.

\section{REFERENCES}

1. Graham DY, Smith JL: Aspirin and the stomach. Ann Intern Med 104:390-398, 1986

2. Lanza FL, Royer GL, Nelson RS: Endoscopic evaluation of the effects of aspirin, buffered aspirin and enteric coated aspirin on gastric and duodenal mucosa. N Engl J Med 303: $135-138,1980$

3. Hoftiezer JW, Silvoso GR, Burks M, Ivey KJ: Comparison of the effects of regular and enteric coated aspirin on gastroduodenal mucosa of man. Lancet ii:609-612, 1980

4. Singleton PT: Salsalate: its role in the management of rheumatic disease. Clin Ther 3:80-101, 1980

5. Leonards JR: Absence of gastrointestinal bleeding following administration of salicylsalicylic acid. J Lab Clin Med 74: 911-914, 1969

6. Cohen A: Fecal blood loss and plasma salicylate study of salicylsalicylic acid and aspirin. J Clin Pharmacol 19:242247, 1979

7. Mielants H, Veys EM, Verbruggen G, Schelstraete K: Comparison of serum salicylate levels and gastrointestinal blood loss between salsalate and other forms of salicylates. Scand J Rheum 10:169-173, 1981

8. Edmar D: Effects of salicylates on the gastric mucosa as revealed by Roentgen examination and the gastrocamera. Acta Radiol (Diagn.) Stockh 11:57-64, 1971

9. Roth GJ, Stanford, N, Majerus PW: Acetylation of prostaglandin synthase by aspirin. Proc Natl Acad Sci USA $72: 3073,1975$

10. Morris HG, Sherman NA, McQuain C, Goldlust MB, Chang SF, Harrison LI: Effects of salsalate (nonacetylated salicylate) and aspirin on serum prostaglandins in humans. Ther Drug Monit 7:435-438, 1985

11. Abrahmson S, Korchak H, Ludwig R, Edelson H, Haines $\mathrm{K}$, Levin RI, Herman R, Rider L, Kimmel S, Weissman G: Modes of action of aspirin-like drugs. Proc Natl Acad Sci USA 82:7227-7231, 1985

12. Estes D, Kaplan K: Lack of platelet effect with the aspirin analog, salsalate. Arthritis Rheum 23:1303-1307, 1986

13. Rowe PH, Starlinger MJ, Kasdon, E, Hollands MJ, Silen W: Parenteral aspirin and sodium salicylate are equally injurious to the rat gastric mucosa. Gastroenterology 93:863-871, 1987

14. Silvoso GR, Ivey KJ, Butt JH, Lockard OO, Holt SD, Sisk C, Baskin WN, Mackercher PA, Hewett J: Incidence of gastric lesions in patients with rheumatic disease on chronic aspirin therapy. Ann Intern Med 91:517-520, 1979

15. Lockard 00, Ivey KJ, Butt JH, Silvoso GR, Sisk C, Holt S: The prevalence of duodenal lesions in patients with rheumatic disease on chronic aspirin therapy. Gastrointest Endosc 26:5-7, 1980

16. Dromgoole SH, Cassell S, Furst DE, Paulus HE: Availability of salicylate from salsalate and aspirin. Clin Pharmacol Ther 34:539-545, 1983 